\title{
Article \\ Computer-Aided Decision Making for Regional Seismic Risk Mitigation Accounting for Limited Economic Resources
}

\author{
Iolanda Nuzzo ${ }^{1, *(\mathbb{C})}$, Nicola Caterino ${ }^{1,2} \mathbb{D}^{-}$, Antonio Novellino ${ }^{3}$ and Antonio Occhiuzzi ${ }^{1,2}$ \\ 1 Institute of Technologies for Construction, Italian National Research Council (CNR), 80146 Naples, Italy; \\ nicola.caterino@uniparthenope.it (N.C.); occhiuzzi@itc.cnr.it (A.O.) \\ 2 Department of Engineering, University of Naples Parthenope, 80143 Naples, Italy \\ 3 ETT S.p.A., 16153 Genova, Italy; antonio.novellino@ettsolutions.com \\ * Correspondence: nuzzo@itc.cnr.it
}

check for updates

Citation: Nuzzo, I.; Caterino, N.; Novellino, A.; Occhiuzzi, A. Computer-Aided Decision Making for Regional Seismic Risk Mitigation Accounting for Limited Economic Resources. Appl. Sci. 2021, 11, 5539. https://doi.org/10.3390/app11125539

Academic Editors: Felice Carlo Ponzo, Rocco Ditommaso, Antonio

Di Cesare, Igal M. Shohet and Panagiotis G. Asteris

Received: 31 March 2021

Accepted: 10 June 2021

Published: 15 June 2021

Publisher's Note: MDPI stays neutral with regard to jurisdictional claims in published maps and institutional affiliations.

Copyright: (c) 2021 by the authors. Licensee MDPI, Basel, Switzerland. This article is an open access article distributed under the terms and conditions of the Creative Commons Attribution (CC BY) license (https:// creativecommons.org/licenses/by/ $4.0 /)$.

\begin{abstract}
Seismic risk mitigation levels for an existing building are a balance between the reduction of risk and the cost of rehabilitation. Evidently, the more that is paid the more risk is reduced; however, due to limited public budgets a practical approach is needed to manage the risk reduction program when a portfolio of buildings is concerned. Basically, decision makers face a challenge when there are a large number of vulnerable buildings and there is no plan for how to allocate the appointed budget. This study develops a technological platform that implements a decision-making procedure to establish how to optimally distribute the budget in order to achieve the maximum possible portfolio risk reduction. Decisions are made based on various presumed intervention strategies dependent on building's level of risk. The technological platform provides an interactive, user-friendly tool, available online, that supports stakeholders and decision makers in understanding what the best economic resource allocation will be after selecting the available budget for a specific portfolio of buildings. In addition, the ease of use enables the user to analyze the extent of risk reduction achievable for different budget levels. Therefore, the web platform represents a powerful tool to accomplish two challenging tasks, namely optimal budget selection and optimal budget allocation to gain territorial seismic risk mitigation.
\end{abstract}

Keywords: regional risk assessment; seismic risk mitigation; seismic risk management; optimal budget allocation; optimal budget selection; prioritization

\section{Introduction}

Disaster risk reduction (DRR) is a global challenge within the urgent context of sustainable development. The inclusion of DRR in policies and economic programs is key to providing cost-effective investment for the prevention of future losses.

EM-DAT [1] reports that 396 natural disasters caused 11,755 deaths, with 95 million people affected and USD 103 billion in economic losses across the world in 2019. The annual average number of deaths, people affected and economic losses in the previous decade (2009-2018) were even higher (45,212 deaths, 184.7 million people affected and USD 176 billion economic losses, respectively), due to the impact of massive disaster events such as the 2010 earthquake in Haiti (222,500 deaths), the 2015-2016 drought in India (330 million people affected) and the 2011 Japan earthquake and tsunami (USD 210 billion in damages). The future projection is for this trend to rise annually and by 2050 be reaching 100,000 lost lives and more than USD 300 billion per year [2]. This increase in vulnerability to disasters is expected due to a number of factors, including worsening socioeconomic conditions, urbanization, environmental degradation, inadequate infrastructures and diseases. According to the last global assessment report [3] on disaster risk reduction, weather-related hazards cause the most economic losses, with floods being the costliest hazard, followed by earthquakes. Meanwhile, losses in the housing sector account for two thirds of total economic losses. 
Global targets and common achievements to pursue DRR have been set in the Sendai Framework for Disaster Risk Reduction 2015-2030 [4], adopted at the Third United Nations World Conference on Disaster Risk Reduction in Sendai, Japan, in March 2015. This aims to achieve a substantial reduction in disaster risk and loss of lives, livelihoods and health, and in the economic, physical, social, cultural and environmental assets of people, businesses, communities and countries over the next 15 years. The Sendai Framework works in continuity with the Hyogo Framework for Action [5] of the previous decade (2005-2015), that recognized DRR as a national and local priority. The Sendai Framework sets seven targets and four priorities for action to prevent new and reduce existing disaster risks: (i) understanding disaster risk; (ii) strengthening disaster risk governance to manage disaster risk; (iii) investing in disaster reduction for resilience; (iv) enhancing disaster preparedness for effective response and to "Build Back Better" in recovery, rehabilitation and reconstruction. The above priorities are rigidly interconnected: the achievement of enhanced disaster preparedness necessitates incisive investments to be driven by an aware management of DRR, based on a deep knowledge of disaster risk. Consequently, pursuing priority (i), understanding disaster risk, is very important since it is necessary for the achievement of each of the other priorities. Among the objectives constituting priority (i), the Sendai Framework requires the development and dissemination of locationbased disaster risk information, including risk maps, to be periodically updated and freely accessible to decision makers, the general public and communities. The United Nation office for disaster risk reduction (UNISDR) developed and launched the Sendai Framework Monitoring System [6], providing an online platform collecting loss data by geographic location. This tool has the potential to provide an important support to the definition of global DRR strategies thanks to data availability, accessibility and interoperability. In order to achieve the global Sendai Framework Monitoring System, UNISDR supports the implementation of national disaster loss data collection systems.

The Italian response to the above requirements, with particular concern to the seismic risk, which is historically among the largest sources of risk for this territory, consists of the development of the IRMA (Italian Risk Maps) WebGIS platform [7,8]. The Italian territory is prone to high seismic risk in many areas due to this significant hazard, the elevated exposure provided by the important building heritage and high population density, and the significantly vulnerable building stock [9]. Indeed, many Italian buildings were realized in the absence of seismic code prescriptions, thus fully lacking horizontal load bearing design criteria. In addition, seismic hazard maps are constantly and continuously updated to more severe levels on the basis of new knowledge acquired by experience and by the development of more refined geological models. Inadequate maintenance further limits structural capacity, worsening the vulnerability of buildings against earthquakes.

The IRMA platform collects national census data about residential building stock and implements several vulnerability/exposure models to evaluate unconditional damage scenarios within two time windows, namely one year and fifty years. In addition, the platform provides the seismic risk impact in terms of direct economic losses, unusable or collapsed buildings and dwellings in the short and long periods and the expected number of homeless, victims and injured people. Such representation of an earthquake's consequences is a very useful support to the definition of seismic risk mitigation policies, helping in the identification of major risk areas requiring higher investments and facilitating the calibration of insurance premiums [7].

Today there are numerous technological strategies that can be adopted in order to achieve satisfactory seismic retrofit levels, thus reducing seismic risk. Although, as pointed out by the Organization for Economic Co-operation and Development [10], the effective financial management of earthquake risk requires governments to consider the best use of their limited resources. As a matter of fact, when the objective is the seismic risk mitigation of a large region where a wide number of buildings may need to be retrofitted, the challenge becomes more financial than technological. The limited amount of available resources generates the crucial issue of establishing how to spend the budget to achieve the highest 
regional seismic risk reduction, knowing that some buildings may not be covered by the retrofit's expense. This leads to a classical optimization problem aimed at finding the optimal trade-off between risk and the resources spent on the risk management program. The optimal decision would be the one minimizing the expected cost while maximum benefit could be yielded.

Many recent studies investigate the use of multi-criteria decision methods (MCDM) within the context of regional seismic risk assessment. Nyimbili et al. [11] applied MCDM within a GIS environment to generate earthquake hazard maps using five main evaluation criteria (field topography, source-to-site distance, soil classification, liquefaction potential and fault/focal mechanism). The authors present the potentiality of integrating such maps with population and building data for the territory in order to provide regional risk information in terms of the potential impacts of earthquake effects. In a different way, Cremen and Galasso [12] combined MCDM and performance-based earthquake engineering (PBEE) in order to provide a viable tool for risk-informed earthquake early warning (EEW). In this case, the evaluation criteria assumed in the MCDM are the casualties, downtime and direct costs, i.e., the results of the PBEE, and are used to compare possible mitigation actions implementable when an EEW system triggers an alarm, finally determining the optimal one. Sadeghi et al. [13] implemented a multi-objective optimization approach based on a genetic algorithm in order to define the optimal mitigation measure for a given return period event according to two issues, i.e., (1) the household annual expenses, such as mandatory earthquake insurance premiums and mitigation costs; and (2) the effects of mitigation measures on saving human lives. A different procedure was introduced by Vona et al. [14], consisting of the use of MCDM to create prioritization strategies to reduce the territorial seismic risk associated with public and strategic buildings. In particular, the proposed methodology compares the convenience of giving priority to the most vulnerable buildings, most exposed buildings (in terms of number of occupants) or to buildings located in the most severe seismic hazard zones. Other authors [15] focused on the assessment of the earthquake risk in historical urban fabrics with commercial value, based on the definition of the "historic-commercial urban fabrics risk index" (HCRI). This index can be estimated locally according to the contribution of hazard, vulnerability and response capacity, which are expressed by means of indicators and sub-indicators weighted through questionnaire surveys or expert judgement. In other studies [16] attention is given to the problem of management and planning of the post-earthquake emergency within an urban area, in order to provide a measure of the resources and equipment needed during rescue activities. The proposed method is based on the availability of damage quantification reports, to be assessed immediately after the event through the completion of specific forms (AeDES forms). None of the above studies addressed the problem of the optimal budget definition and allocation for regional seismic risk mitigation. Motamed et al. [17] proposed an automated model for optimizing budget allocation in earthquake mitigation scenarios through an iterative procedure looking for a retrofitting strategy with a cost within the available budget. The procedure integrates HAZUS vulnerability classes and parameters for several building typologies, similarly to the method proposed by Zolfaghari and Peyghaleh [18] that additionally introduced the concept of equity in the distribution of resources among different groups of people. In the approach proposed by Caterino et al. [19], the optimal budget allocation for seismic risk mitigation was achieved through the analysis of a wide range of possible retrofit strategies for the buildings stock, based on the seismic vulnerability of each building. This allows for a dense cloud of cost-benefit scenarios to be obtained, where the cost corresponds to the needed territorial investment and the benefit is the achieved seismic risk mitigation. The optimal retrofit solution can be selected among the possible scenarios as the one that allows minimization of the seismic risk given the available budget. This procedure can provide significant support to decision makers in planning appropriate seismic risk mitigation strategies since they are able to provide a global and comprehensive overview of the costs and benefits associated with a very large number of different scenarios. However, handling the huge amount of data that is 
consequent to the application of this procedure is a challenging task that can discourage its effective use. Indeed, differently to the methodologies suggested in $[17,18]$, where loss analyses are performed by means of the HAZUS external tool, in [19] the seismic risk and loss assessment is performed for each building belonging to the portfolio. This implies that not only does the output cost-benefit analysis generate a large amount of information, but also managing the input data could be an issue. This is the motivation behind the present work that integrates and organizes the procedure proposed in [19] on an Italian georeferenced platform, freely available online, allowing an interactive implementation of a decision-making assessment for the prioritization of regional seismic retrofit interventions, satisfying a financial constraint. Basically, the decision process is divided into two sections: (1) collection of building stock data to perform seismic risk assessment and calculate the risk of failure at each building of class and then (2) management and mitigation of seismic risk through prioritization of interventions and optimal budget allocation. Decision making concerns any intervention for all included buildings that may or may not be subjected to the seismic retrofit, based on the defined strategy to reduce the expected future loss. The platform is herein presented for the case study of a school building's stock in the Campania region in south Italy, but it could be customized for any typology of building portfolio in any area. An interactive tab enables the user to select the available budget for the risk mitigation investment: as a result, the platform returns the optimal seismic retrofit strategy to be adopted for each building belonging to the portfolio under study. In addition, the evolution of territorial seismic risk in the post-retrofit environment is shown on the Campania region map, allowing a prompt comparison with respect to the initial (i.e., pre-retrofit) seismic risk. Not only budget allocation but also budget selection can be a challenging task within the DRR framework. An insight about this topic is herein provided through a sensitivity analysis about budget variation and consequent adopted retrofit strategies and achievable risk reduction.

The platform has been developed within GRISIS project-Risks and Safety Management of Infrastructures at Regional Scale. This project is based on a multidisciplinary approach to achieve a holistic analysis of both natural and anthropic risks on civil infrastructure in the Campania region in south Italy.

\section{Regional Seismic Risk: Assessment and Mitigation through a Simplified Procedure}

The procedure proposed in [19] for the optimal seismic risk mitigation of a portfolio of reinforced concrete frame buildings is adopted in the development of the present platform and summarized in the present section. It is formulated in five main blocks, concerning building stock definition, vulnerability assessment, pre-intervention seismic risk analysis, cost-benefit seismic risk mitigation analysis and optimal budget allocation analysis, respectively. The procedure is synthetized in the flowchart of Figure 1. 


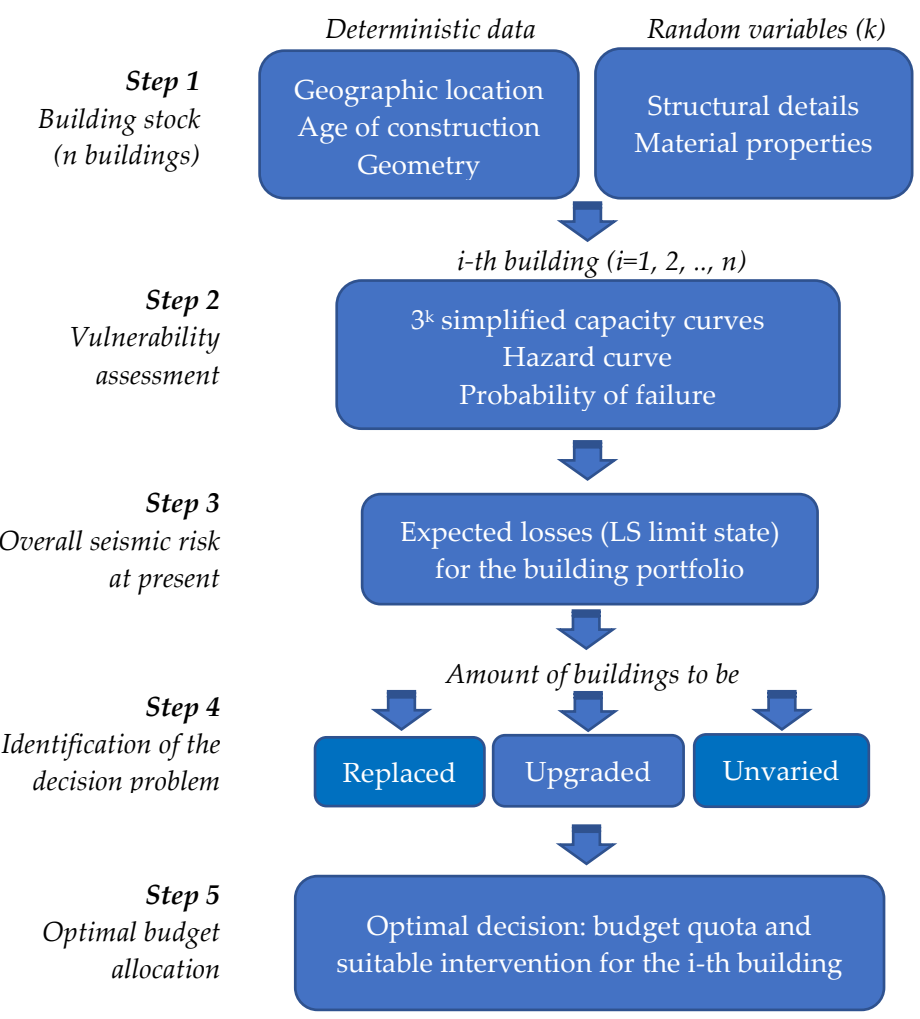

Figure 1. Flowchart of the simplified procedure for regional seismic risk assessment and mitigation.

\subsection{Building Stock Definition}

Regional seismic risk assessment requires finding a reasonable compromise between the completeness of building information and correctness of analysis results. In the procedure assumed in this work, the following data are needed for each building: geographical location, age of construction, geometry in plan and elevation (number of storeys, total height and width, number of frame bays and bay length), structural details (columns and beams cross-section and reinforcement) and material's strengths. Considering that the first three types of information could be easily collected in a reasonable time window by survey or from national census, they are considered as deterministic data, assumed to be known. In a different way, the knowledge about materials and detailing from original design documents is probably not accessible without carrying out destruction tests on structural members. Considering the unfeasibility of this type of investigation in largescale seismic risk analysis, these data are considered to be unknown. They are treated as random variables (RV) with probability distributions characterized by mean value $\mu$ and standard deviation $\sigma$ that can be assumed on the basis of eventual available data in design documents, related references or expert judgement in relation to the known age of construction. The full factorial design method is assumed in the procedure for the design of experiments [20] and three points are chosen for each RV (namely $\mu, \mu+\sigma, \mu-\sigma$ ). Consequently, $3^{\mathrm{k}}$ possible realizations of each building are considered in the process, where $\mathrm{k}$ is the number of RV. In the procedure proposed in [19], $11 \mathrm{RVs}$ are assumed, thus leading to $3^{11}=177^{\prime} 147$ realizations for each building. This high number allows decision makers to take into account uncertainty about the effective structural details and materials.

\subsection{Vulnerability Assessment}

Seismic hazard is defined assuming 9 return period events according to Italian code [21] for each site location of interest, getting $\Delta \bar{\lambda}^{i}\left(s_{j}\right)$, which is the mean annual frequency of earthquake occurrence exceeding ground motion intensity $\mathrm{s}_{\mathrm{j}}$. Vulnerability assessment is performed for each $\mathrm{m}$-th realization of a specific building by means of the simplified SP-BELA method [22], thus obtaining $3^{\mathrm{k}}$ capacity curves concerning one 
structure. Successively, given a specific return period, capacity spectrum method [23] is applied to assess whether the $m$-th structural system fails $\left(C_{m}<D_{m, j}\right)$ or not $\left(C_{m} \geq D_{m, j}\right)$. The total number of failures weighted by the probability of occurrence of each realization of random variables allows decision makers to find the probability of failure of each i-th building $P F_{\text {pre-int }}^{i}\left(s_{j}\right)$, in correspondence with each of the nine return periods, assessed at Life Safety (LS) limit state (NTC 2018). Then, the nine points are fitted assuming for $P F_{\text {pre-int }}^{i}\left(s_{j}\right)$ a normal cumulative distribution function, finally achieving the fragility curve for the given building (Figure 2).

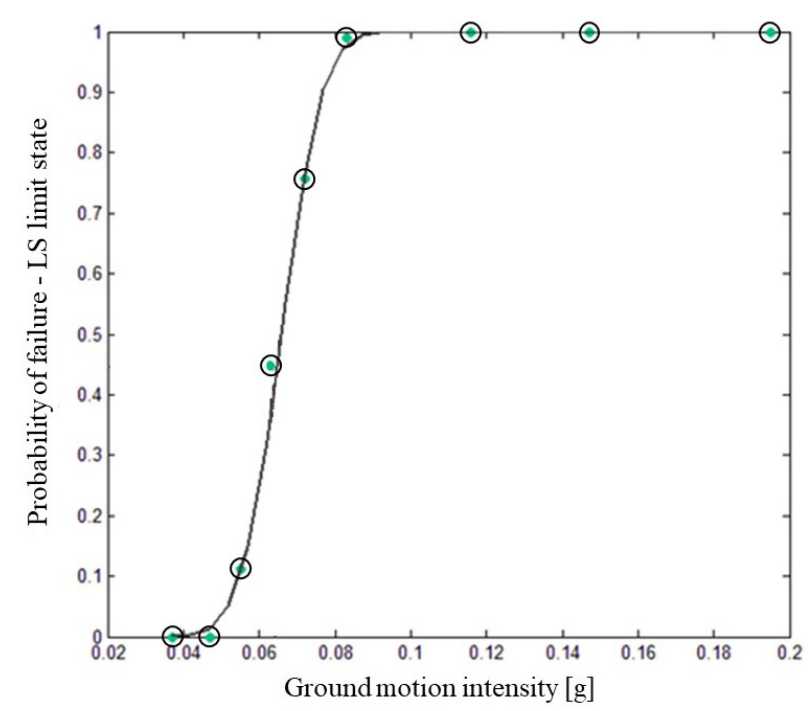

Figure 2. Fragility curve by regression of points related to nine seismic intensities.

The fragility curves derive from the comparison of capacity and demand, where the first is determined performing a wide number of structural analyses assuming several sets of random variables, while the latter comes from a probabilistic modelling of seismic hazard. This approach allows decision makers to take uncertainty into account in terms of capacity and demand definition.

At this point, for each i-th building, the mean annual frequency of exceeding LS limit state can be calculated

$$
\lambda_{\text {pre-int }}^{\mathrm{i}} \cong \sum_{\mathrm{j}=1}^{9}\left[\Delta \bar{\lambda}^{\mathrm{i}}\left(\mathrm{s}_{\mathrm{j}}\right) \mathrm{PF}_{\text {pre-int }}^{\mathrm{i}}\left(\mathrm{s}_{\mathrm{j}}\right)\right]
$$

\subsection{Pre-Intervention Seismic Risk Analysis}

In order to find the initial regional seismic risk, it is first necessary to define exposure. In [19], exposure is assumed to be related to the overall floor area of the given building, while the economic expected loss at LS state $E\left[\mathrm{~L}_{\mathrm{i}} \mid \mathrm{DS}=\mathrm{LS}\right]$ is calculated as $75 \%$ of replacement value of the building. In particular, damage at Life Safety limit state is assumed to be $3 / 4$ (i.e., $75 \%$ ) of damage at Collapse limit state, unavoidably corresponding to a replacement cost, in coherence with the indication of the EC8 [24] of assuming plastic rotation at Life Safety limit state to be $3 / 4$ of the plastic rotation at Collapse limit state. According to some regional previous studies in Italy, the replacement value is assumed to be equal to $1500 \mathrm{EUR} / \mathrm{m}^{2}$ [25]. At this point it is possible to calculate the total seismic risk and the sum of the seismic risks associated to each i-th building

$$
S R_{\text {pre-int }}=\sum_{i=1}^{n} S R_{\text {pre-int }}^{i}=\sum_{i=1}^{\mathrm{n}}\left(E[L i \mid D S=L S] \lambda_{\text {pre-int }}^{i}\right)
$$




\subsection{Cost-Benefit Seismic Risk Mitigation Analysis}

Successively, the vulnerability index of the i-th building before making any intervention can be determined as follows

$$
\chi_{\text {pre-int }}^{\mathrm{i}}=\frac{\lambda_{\mathrm{SL}}}{\lambda_{\text {pre-int }}^{\mathrm{i}}}
$$

where $\lambda_{S L}$ is the maximum allowable frequency of failure [26].

According to the obtained value of vulnerability indices, a decision measure has to be made for all the possible cases according to Table 1.

Table 1. Decision solutions according to the initial vulnerability index.

\begin{tabular}{ccc}
\hline Case 1: & $\chi_{\mathrm{i}} \leq 0.2$ & (1) Demolition and reconstruction \\
\hline Case 2: & $0.2<\chi_{\mathrm{i}}<0.7$ & (1) No intervention (2) Partial retrofitting and \\
& $0.7 \leq \chi_{\mathrm{i}}<0.8$ & (1) Full retrofitting \\
\hline Case 3: & $\chi_{\mathrm{i}} \geq 0.8$ & (1) No intervention and (2) Full retrofitting \\
\hline Case 4: & & (1) Nention \\
\hline
\end{tabular}

The definition "No intervention" $(\mathrm{N})$ indicates that the building is left as it is, so no retrofitting cost is needed. Any possible retrofitting option which makes the capacity of building to be at least equal to the demand $(x=1.0)$ would satisfy the condition of full retrofitting $(F)$. Alternatively, a lower level of target design $(\chi=0.7)$ could be obtained by means of a partial retrofit $(\mathrm{P})$, so that less of the retrofitting budget goes to any building in the portfolio. When the vulnerability index is very low $\left(\chi_{i} \leq 0.2\right)$, buildings might be demolished and rebuilt (D) because they are considered as extremely risky (case 1 ). The new building would be designed and constructed according to the new building code, thus satisfying the minimum requirements of the seismic design criteria. Contrarily, when the vulnerability index is high enough $\left(\chi_{i} \geq 0.8\right)$, no interventions $(N)$ are programmed (case 4) [21]. Case 2 includes a vast range of vulnerability scenarios: in this case, three possible interventions are admitted, i.e., $\mathrm{P}, \mathrm{F}$ or $\mathrm{N}$. This allows decision makers to consider the circumstance in which very limited budget is available, thus requiring them to leave some buildings as they are, or to perform just a partial retrofit. When the vulnerability index is slightly lower than the admitted level $\left(0.7 \leq \chi_{i}<0.8\right)$, only full retrofit or no-intervention are possible decision strategies.

Partial and full retrofitting cost is estimated as a partial amount of reconstruction cost, adopting specific cost models [27] as a function of the vulnerability index (the more vulnerable a building is, the larger the amount of money that needs to be paid to repair) and year of construction [19].

Finally, the post-retrofit seismic risk of each building is calculated assuming the probability of exceeding LS damage state of i-th building when it is decided to be repaired, either partially or fully, determined from the pre-intervention probability of failure multiplied by a scale factor [19]. The regional seismic risk in the post-retrofit scenario is the sum of the seismic risk associated to each building. The total cost due to seismic risk mitigation of the portfolio corresponds to the summation of the single intervention cost for each building.

On the basis of the possible decision strategies to be assumed for each building belonging to the portfolio, several combinations are obtained depending on the number of buildings falling within case 1 to 4 according to Table 1 . If $n$ is the total number of buildings and letters $a$ to $d$ represent the number of buildings characterized by a vulnerability index belonging to the range of cases 1 to 4 , respectively, the total number of combinations of the portfolio retrofit decisions would be $\mathrm{Q}=1^{\mathrm{a}} \times 3^{\mathrm{b}} \times 2^{\mathrm{c}} \times 1^{\mathrm{d}}$. Each combination corresponds to a total retrofitting cost accounting for all the portfolio interventions and a total postintervention seismic risk. This allows decision makers to construct a cost-benefit curve similar to the illustrative curve provided in Figure 3, where each dot indicator represents 
one single combination among the possible $Q$ combinations. As the investment spent for retrofitting increases, the seismic risk is reduced, thus providing a constant downward trend in the cost-risk relationship. The initial seismic risk (i.e., before adopting mitigation strategies) is the highest point of the curve, as it corresponds to the status quo, thus zero cost of intervention: this is the benchmark condition to assess the adequateness of retrofit strategies to reduce the whole seismic risk.

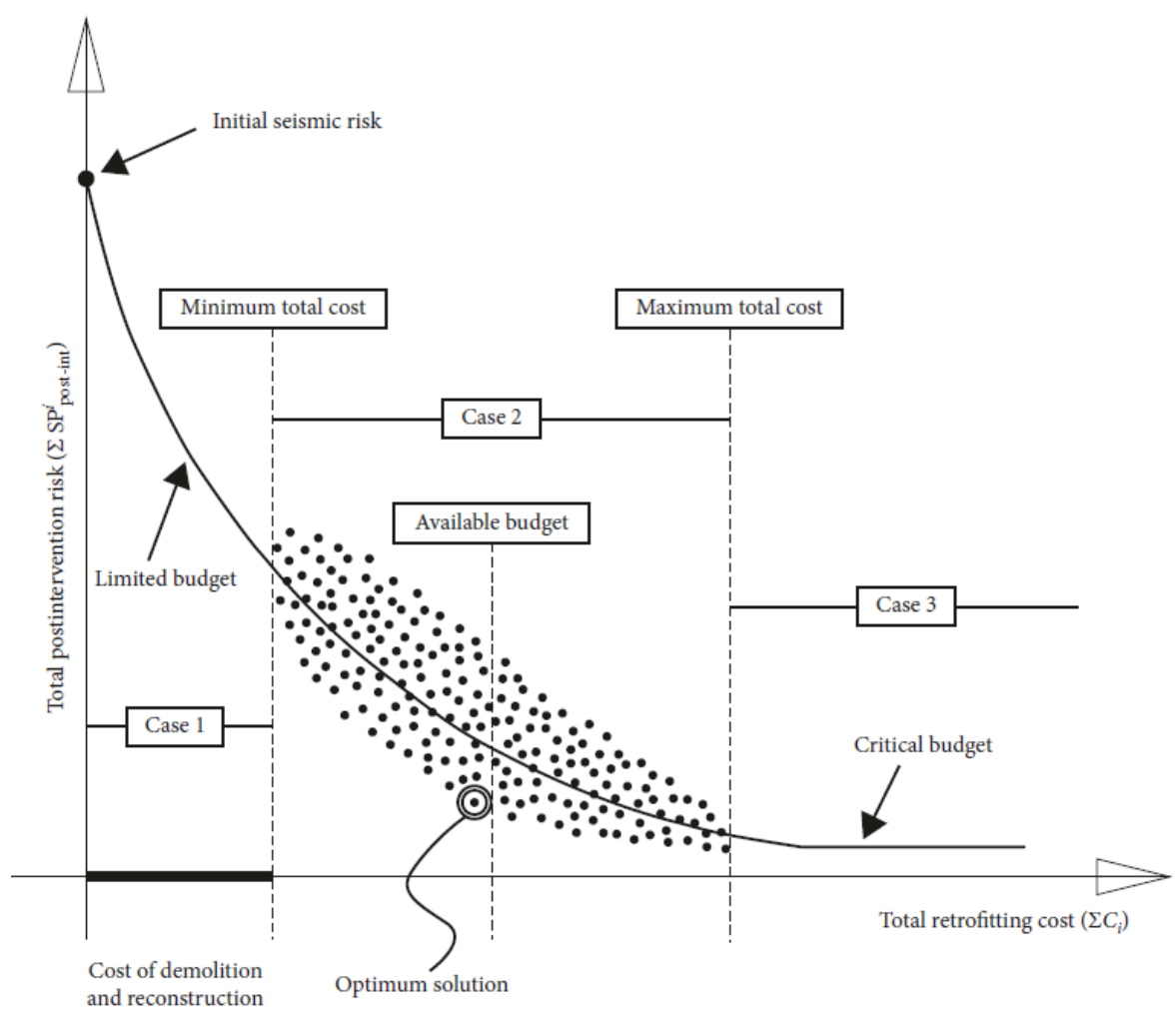

Figure 3. Total retrofitting cost versus total post-intervention seismic risk [19].

\subsection{Optimal Budget Allocation}

In the budgeting phase, it is necessary to know the results of simulations such as those herein presented. First of all, it is necessary to identify the "minimum" and "maximum" values. The minimum total cost (Figure 3; "Min Tot Cost" in Equation (4)) is that which is required to solve the most urgent problems, which are the demolition and reconstruction of the highest risk buildings (i.e., those with $\chi_{i} \leq 0.2$ ). The maximum total cost corresponds to the cost needed to provide all buildings with a vulnerability index greater than or equal to the allowable value 0.8 (Figure 3; "Max Tot Cost" in Equation (4)). The budget to be invested should not exceed the maximum value unless it is decided to increase the allowable value of the capacity / demand ratio beyond 0.8 (case 3 in Figure 3). Once the investment has been established, the optimal allocation has to be found that leads to the most effective reduction of the overall seismic risk. If the available budget is below the minimum value, the decision is unambiguous, that is demolishing and rebuilding the largest number of buildings with $\chi_{i} \leq 0.2$, until the budget is exhausted, giving them priority according to their own $\chi_{i}$ value. If the available budget belongs to the range between minimum and maximum values (case 2 in Figure 3), it is necessary to identify the best solution through the optimization of the budget allocation. The best solution is the set of interventions for each building that allow minimizing of the overall post-intervention seismic risk ( $\left.\mathrm{SR}_{\text {post-int }}\right)$ while the total retrofitting costs $\left(\mathrm{C}_{\text {tot }}\right)$ remain within the available budget (optimal solution 
in Figure 3). The above logic for sharing the budget and deciding the optimal intervention for each building is summarized in Equation (4).

$$
\begin{gathered}
\text { if } \rightarrow \text { Available Budget } \leq \text { Min Tot Cost } \\
\text { then } \rightarrow \text { Demolition and Reconstruction of the largest number of } \\
\text { buildings with } \chi_{\mathrm{i}} \leq 0.2 \text {, until the budget is exhausted } \\
\text { if } \rightarrow \text { Min Tot Cost } \leq \text { Available Budget } \leq \text { Max Tot Cost } \\
\text { then } \rightarrow \text { best solution: } \text { minSR } \text { post-int subject to } C_{\text {tot }} \leq \text { Available budget }
\end{gathered}
$$

\section{A Technological Platform to Manage Regional Seismic Risk Accounting for Available Economic Resources}

To facilitate the spread of the practical use of the procedure described above for seismic risk mitigation on a territorial scale, it is crucial to have the support of a valid operational IT tool, with a simple and effective interface for the user. Within a European research project called GRISIS (Risk Management and Safety of Infrastructures at a regional scale), a technological platform has been used to assess and manage natural and anthropic risks at regional scale within a unique tool. The prototype release of such a tool focuses on the territorial area of the Campania region in southern Italy and involves seismic, hydrogeological, environmental risks as well as that associated with the potential collapse of human infrastructures like telecommunication networks.

The GRISIS backend data management combines technologies and features to integrate and make available IoT, geo-referred data, reprocessed data and products. The backend integrates data services and catalogues such as GeoServer, THREDDS Data Server and ERDDAP, which also implement system layers for machine-to-machine interoperability according to OGC standards. On top of this backend private-cloud infrastructure, a webGIS portal provides a gateway to data, metadata and data products. It provides digital maps, with panning, zooming and selecting features allowing users to view and interact with data products, with full metadata including links to retrieve further documentation and references. These features are designed to help users and providers understand the density and typology of measurements where there are data gaps, etc. The portal front end is developed in Angular using Leaflet libraries, and it is compliant to the Web Content Accessibility Guidelines 2.0 of the World Wide Web Consortium (W3C) [28].

The homepage of the platform shows the geographic map of the territory of interest, as shown in Figure 4. It is a dynamic map with three control/filters areas and each item (dots, lines, shape) is interactive. From the menu on the left it is possible to select the type of risk to be analyzed, allowing to contemporarily display and overlap different levels of information on the map. Legends appear on the right of the map according to the selected typology of risk. 


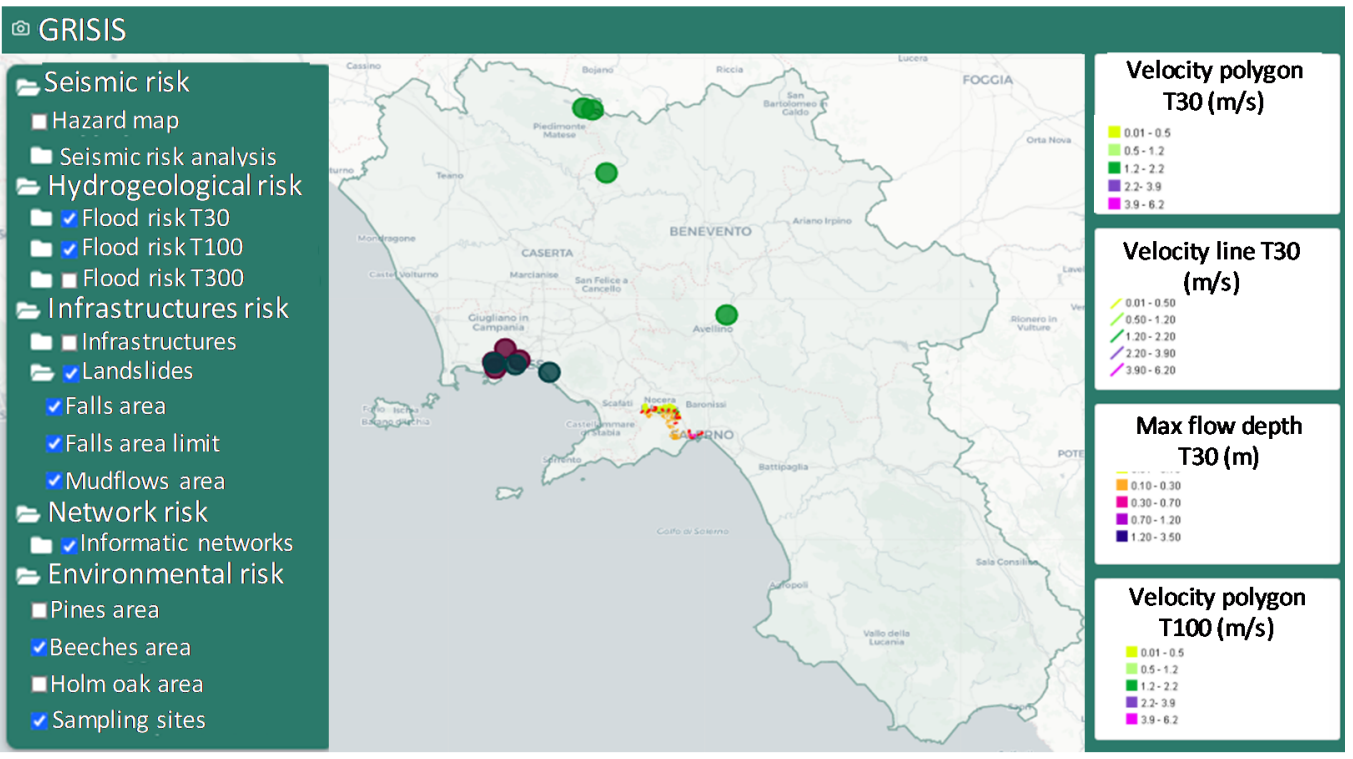

Figure 4. Platform metadata.

The multi-risk platform presents a specific section implementing the decision-making tool for the management and mitigation of regional seismic risk of a portfolio of buildings. It is available online (http:/ /151.1.25.86/GrisisWeb / Rischio, accessed on 14 June 2021) and it collects geo-referenced information and data about buildings belonging to a specific portfolio, which can be consulted by users on practical maps. Such data correspond to the input information required to apply the framework proposed in [19] and described in the previous section, i.e., site location, age of construction and frame geometry. Geographical coordinates of buildings are needed to get information about local seismic hazards: to simplify this step, seismic hazard gridded maps are integrated in the platform (Figure 5), presenting the peak ground acceleration (PGA) in false colors with a grid resolution of $4 \mathrm{~km}$ by $4 \mathrm{~km}$. Clicking on an indicator opens the data panel and shows the PGA value for the selected grid cell.

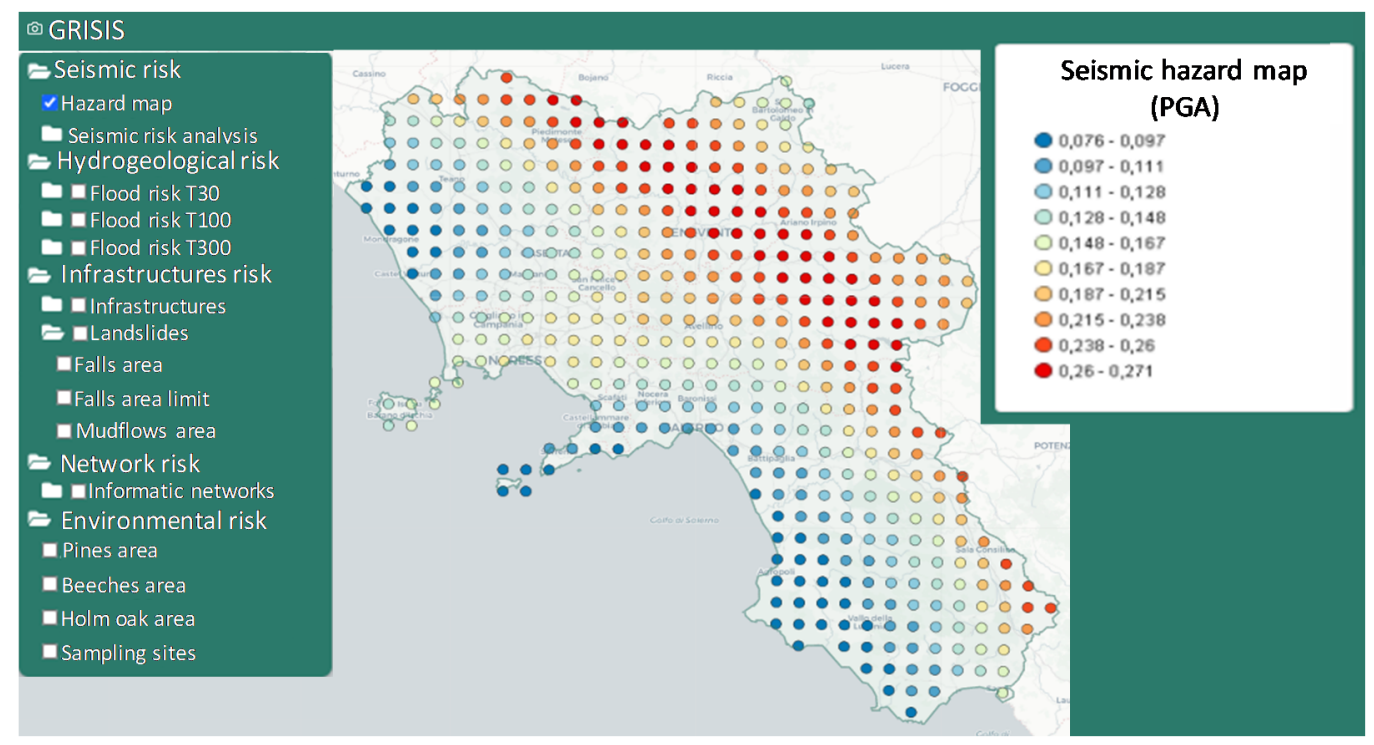

Figure 5. Seismic hazard map.

The decision-making platform is composed of a graphical section and an information portal (Figure 6). The former includes three different maps of the area of interest that show 
the pre- and post-intervention seismic risk and the type of retrofit intervention for each building, respectively. In particular, each colored dot on these maps represents a building belonging to the portfolio and the interpretation of the information it provides can be read on each map by means of the relative legends. This section also includes the cloud of cost-benefit scenarios correlating to the total seismic risk and the total investment.

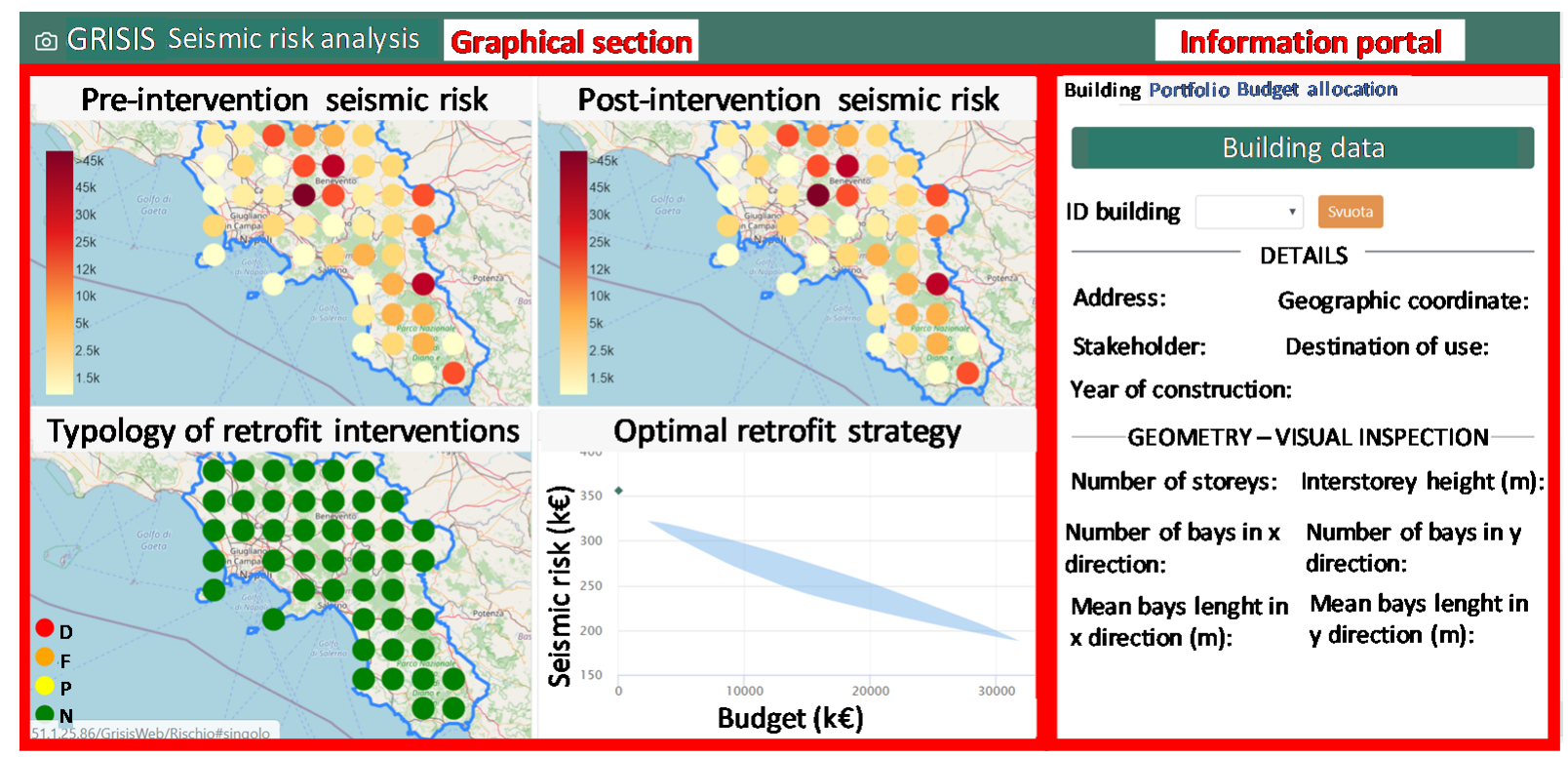

Figure 6. Web-platform analyzing the seismic risk of a buildings portfolio and prioritizing retrofit interventions to mitigate it.

The information panel on the right side of the platform is composed of three different tabs. In the first (Figure 7a), building data concerning its identity (address and geographical coordinates, stakeholder's name, destination of use and year of construction) and geometry (number of storeys, interstorey height, number of bays, mean length of bay) are collected. The statistical occurrence of these date in the portfolio is shown in the second tab (Figure 7b), thus providing the user with an overall view of the portfolio's main characteristics. At this point, all the needed information to start the portfolio seismic risk assessment has been gathered and the framework can be applied after assuming probabilistic distributions of the $11 \mathrm{RVs}$ involved. At this stage of the research, the algorithms behind the procedure have not been integrated in the platform, instead they have been elaborated through external MATLAB codes. The results of the pre-intervention seismic risk assessment are then shown on the graphical section (Figure 6) both by a regional map, where each building is represented by a scale-colored dot corresponding to a certain extent of risk, and on the cost-benefit curve as the seismic risk corresponding to zero-cost investment (scatter point on the vertical axis). The outcomes of the post-intervention seismic risk assessment can be analyzed by the user through the third tab of the information panel (Figure 7c), which is interactive allowing the user to insert the desired budget to be invested for the seismic risk mitigation. On the basis of this value, the system provides the optimal retrofitting strategy, updating the post-intervention seismic risk and type of intervention maps of the graphical section. The corresponding total seismic risk of the overall portfolio is indicated on the cost-benefit plot in correspondence with the user-selected budget value. Moreover, additional pie charts showing the occurrence of intervention typologies and the budget allocation in correspondence with each of them are provided in the third tab (Figure 7c). Moving the cursor on the maps, a summary of initial and post-intervention seismic risk is shown in correspondence with a specific ID building, together with the type of intervention and the relative cost. As well as this, the optimal strategy on the cost-benefit plot is further detailed recalling the amount of the investment and the initial and post-intervention total seismic risk (see Figure 8). 


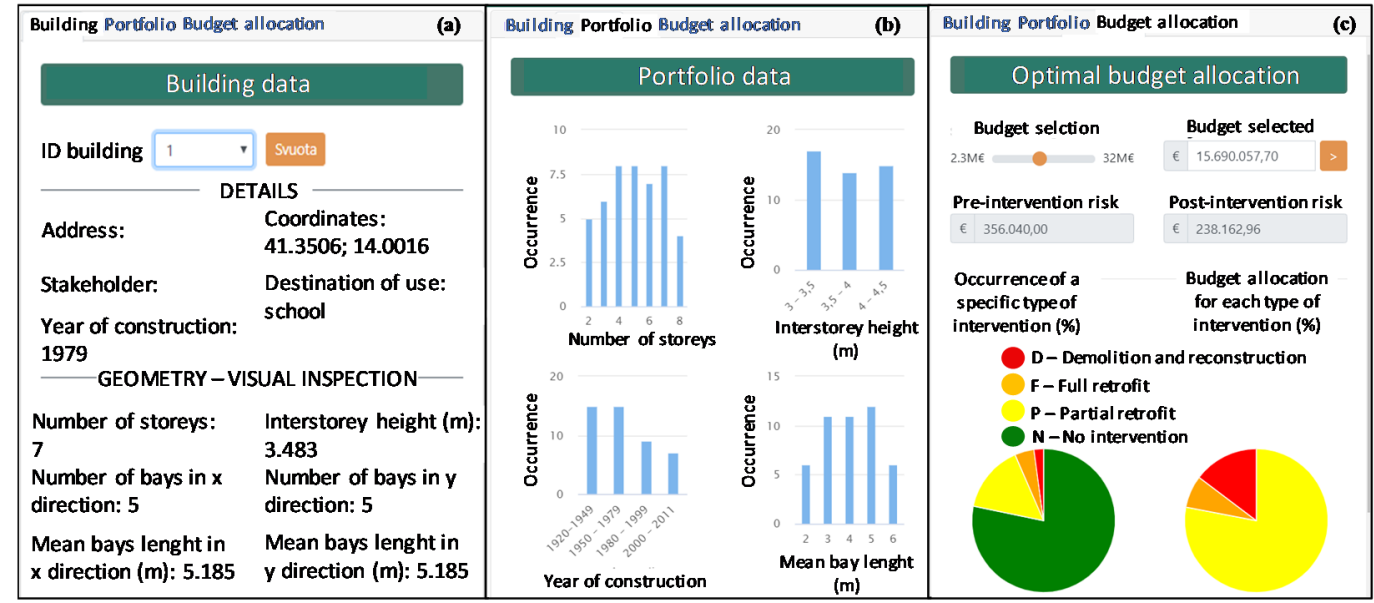

Figure 7. Information portal: (a) building's registration data; (b) portfolio main characteristics; (c) interactive budget allocation.

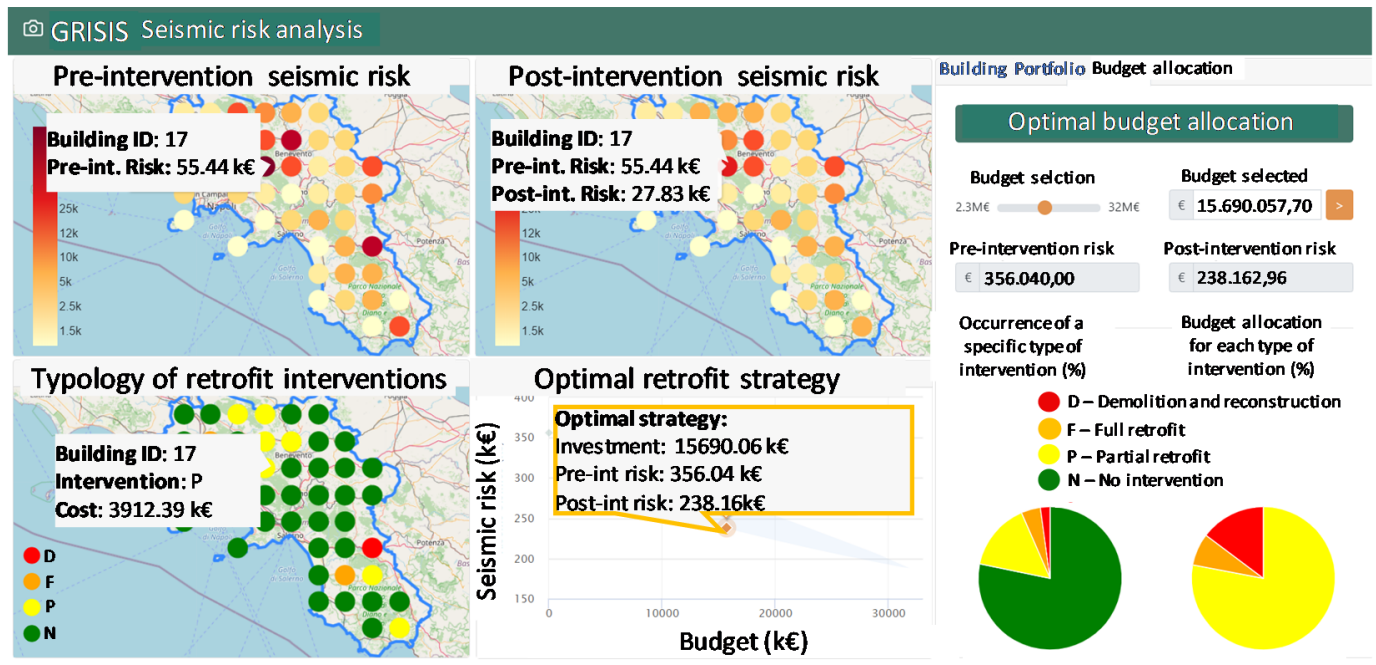

Figure 8. Interactive budget allocation and maps updating.

In summary, input and output data in the decision-making platform for optimal seismic risk mitigation are listed in Table 2.

Table 2. Summary of input and output data of the decision-making tool.

\section{Input Data}

- $\quad$ Geo-referenced ID and geometry buildings

data

- Seismic hazard

- Available budget

\section{Output Data}

- Pre-intervention seismic risk for each building and for overall portfolio

- Optimal budget allocation:

- Type of intervention and relative cost for each building Occurrence of intervention typologies in the portfolio

Budget allocation for each type of intervention

Post-intervention seismic risk for each building and for overall portfolio

\section{Example Application of the Prototype Decision-Making Platform}

The prototype platform has been tested by making a first application with reference to a simulated building stock: a set of $46 \mathrm{RC}$ school buildings ideally and uniformly distributed over the territory of the Campania region. Deterministic data are intended to be presumed by means of visual inspection and/or original design documentation. The variability of random parameters concerning structural details and materials is expressed through probability distributions assumed from relevant literature or by expert judgment, 
distinguishing two different classes of buildings according to their year of construction (namely pre or post 1972). More details can be found in [19].

The pre-intervention seismic risk assessment and the cost-benefit seismic risk mitigation analysis were performed and the relative results provided through the web platform in a direct and graphical supported approach, thanks to the interactive user-friendly interface. The main objective and potentiality of this tool is to allocate the budget to the right place so the client should know how much they should spend on each building and what would be the best decision strategy to intervene. Hence, the final report of the decision-making process should be able to provide (i) the suggested intervention strategy for each building (demolition/reconstruction, no intervention, partial retrofitting or full retrofitting); (ii) the cost to be paid for each building according to the required retrofit option; (iii) the total cost to be invested, which must obviously be lower than the available budget; (iv) the reduced seismic risk ( $\left.\mathrm{SR}_{\text {post-int }}\right)$, as well as the initial risk $\left(\mathrm{SR}_{\text {pre-int }}\right)$, provided to appreciate the total seismic risk mitigation achieved.

Assuming an available budget equal to EUR $2.5 \times 10^{7}$, the suggested retrofit intervention for each building, maximizing the seismic risk mitigation, is provided in Figure 9 . The seismic risk distribution on the area of interest allows for a prompt and clear summary of the most vulnerable buildings in the pre-intervention condition (top map on left side) and the achievable mitigation (top map on right side) thanks to the suggested retrofit interventions (bottom map on left side). In addition, moving the cursor on the pie charts in the bottom right side of the platform provides a picture of the distribution of interventions and corresponding budget allocation (Figure 10). In this case, it appears that, for the available budget, $28.3 \%$ of buildings were subjected to interventions, with only one building needing to be demolished and rebuilt and an equal number of buildings (six) being partially and fully retrofitted. The biggest amount of the budget was spent in order to fully recover the six identified buildings, while half of this amount was required for the partial retrofit of the other six buildings. The rest of the budget (around 10\%) was spent on the demolition and reconstruction of the most vulnerable building. The biggest part of the portfolio (almost $72 \%)$ was left as it was. This strategy allowed for the achievement of a total seismic risk reduction of $41.8 \%$, decreasing the initial seismic risk $\left(\mathrm{SR}_{\text {pre-int }}=356.04 \mathrm{k} €\right)$ to the final value of $S_{\text {post-int }}=207.03 \mathrm{k} €$, as provided on the cost-risk curve of the platform.

Modifying the amount of budget enables the user to analyze what the optimal use is and the corresponding extent of seismic risk mitigation. Consequently, the presented platform allows not only to support stakeholders to solve the decision-making problem of optimal budget allocation, but also to analyze several possible scenarios considering different amounts of budget. From this perspective, the platform can be used as a tool to achieve the optimal budget selection. In general, the expected trend is that the higher the available investment, the bigger the seismic risk reduction and the number of possible retrofit interventions will be. However, it could happen that within certain ranges of budget values the achievable seismic risk reduction, even if improving, does not vary significantly. This condition may be observed when the available budget is incremented to a given amount that results in it not being adequate to support further full retrofit interventions, thus limiting its use, for example, for just partial retrofitting. A specific sensitivity analysis is addressed in the next section to investigate the variability of risk reduction with the budget variation. 


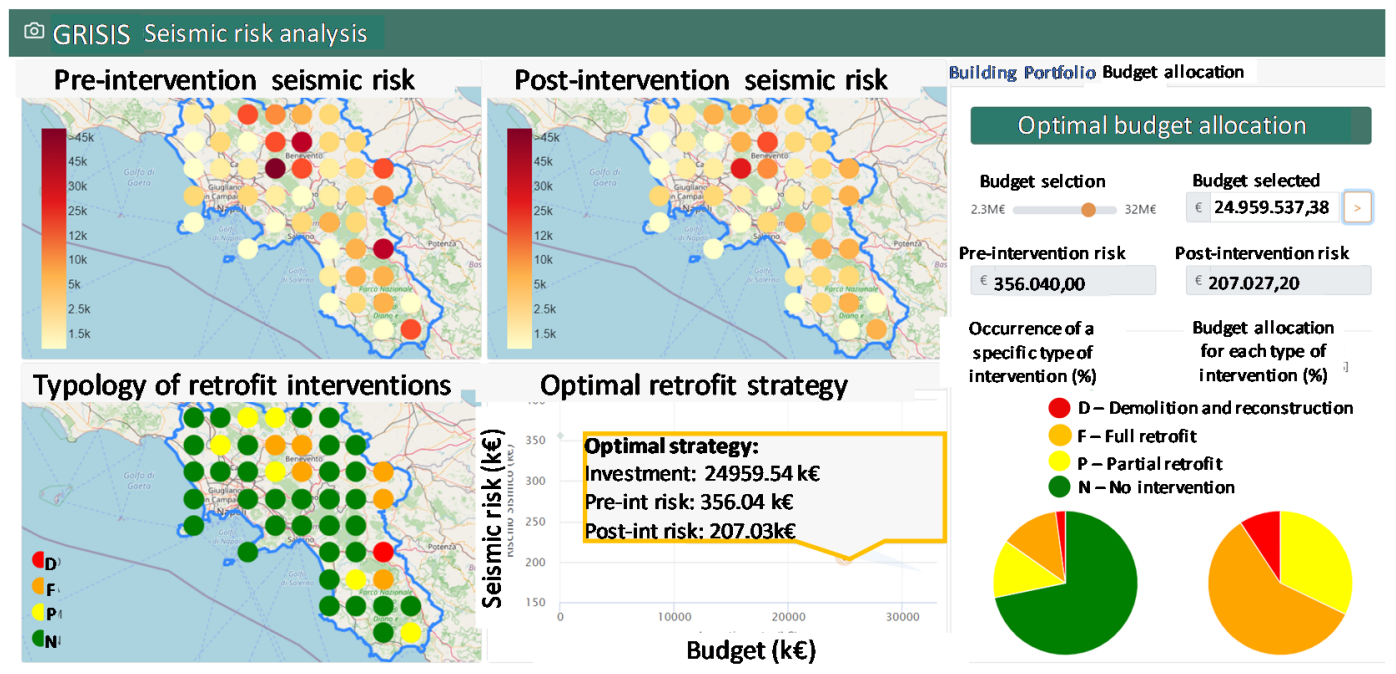

Figure 9. Optimal budget allocation for an investment of $2.5 \times 10^{7} €$.

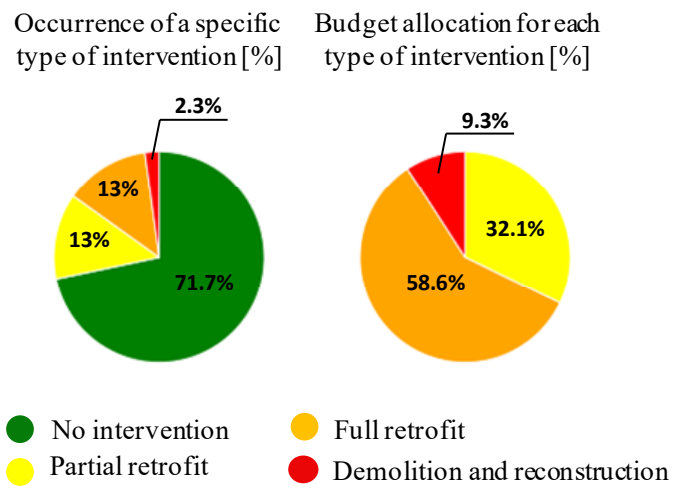

Figure 10. Optimal intervention strategy for a budget of $2.5 \times 10^{7} €$.

\section{Sensitivity Analysis in Capital Budgeting for Territorial Seismic Risk Mitigation}

The budget allocation for the retrofitting of portfolio RC buildings shown above was performed by assuming a hypothetical budget value. The choice of intervention for each single building is a function of the budget limit when the minimum risk of optimum solution is chosen according to the constraint. Thus, changing the budget value may change the decision of intervention. Actually, for this type of decision-making problem, the budget is assumed to be known. However, in some projects spending a partial amount of budget might be more appropriate than the whole. Hence, that would be a complementary analysis of the budget allocation to see if spending a different amount than the budget might change the final decision remarkably or not. The sensitivity analysis reported here was not made to find out which parameters had more impact on the final decision but to figure out how just one parameter (i.e., budget) could affect the final decision. The electronic platform can be of great use to achieve this goal.

The analysis was conducted by changing the budget level in different discretized values from the minimum total cost to maximum total cost value. The former corresponds to the needed cost to achieve a minimum global seismic risk mitigation. Conversely, the maximum total cost is the investment allowing to upgrade seismic capacity of all buildings up to the full satisfaction, that in this framework was set to be the achievement of a vulnerability index $\chi_{i} \geq 0.8$. Indeed, in this case, no further interventions were suggested to furtherly reduce seismic risk, matching the Italian national requirements [21].

Two decision parameters were considered to observe the effect of budget variation on the final decision: (1) number of buildings involved in a decision strategy by spending 
any amount of budget rate and (2) total risk reduction achieved in comparison to the initial total risk level.

The effect of budget variation on the two selected decision parameters for the case study presented in the previous section is shown in Figure 11 starting from zero budget to the maximum possible investment for the project. The variation in the number of buildings involved in each of the four decision strategies and the corresponding seismic risk reduction due to the amount of investment are depicted.

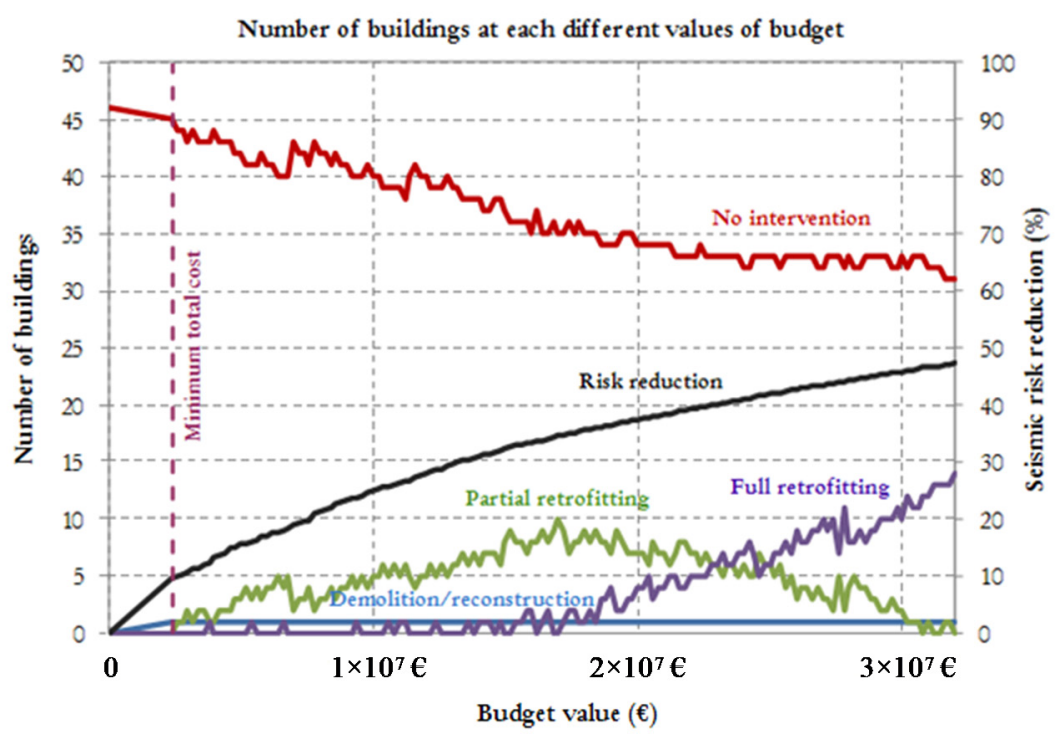

Figure 11. Sensitivity of number of buildings at each decision strategy and total risk reduction to the budget variation.

If the budget is lower than the minimum total cost, all the buildings are in the condition of no intervention. In the case of a very limited budget, at least equal to the minimum total cost, it is not possible to intervene in all the buildings. Then, retrofit actions would be the first preferred option for the most vulnerable buildings $(x \leq 0.2)$, to be sorted according to the lowest vulnerability indices corresponding to the most urgent buildings for intervention. In this case study, there was only one building needing to be demolished and rebuilt with a minimum cost of EUR 2.4 million, while the other 45 buildings were left in the condition of status quo. In this scenario a seismic risk reduction of $9.56 \%$ was achieved. In correspondence with the maximum total cost, the risk reduction could achieve the maximum value of $47.2 \%$. This limit value is influenced by the choice, made in the framework, to stop the retrofit interventions on the buildings when their vulnerability indexes achieve the value of 0.8 . This means that further increases in the investment would not contribute to furtherly reduce the seismic risk, provided that the decision would always result in "no intervention". Spending any budget amount in between the minimum and the maximum total cost allows intervention on a specific number of buildings with any of the presumed intervention strategies. The number of buildings with no interventions evidently tends to decrease as the budget increases, in favor of the number of buildings with partial or full retrofitting programs. In particular, for lower values of the budget, the number of partial retrofitted buildings is higher than the number of fully retrofitted ones, while this condition is inverted from a certain threshold (around $2.5 \times 10^{7} €$ ). Indeed, the increase in budget constantly makes for an increase in full retrofitting instead of partial retrofitting solutions. In addition, there is an indented trend on both curves that is explained by the philosophy within the framework, according to which is the priority to intervene first on those buildings with the highest vulnerability. For instance, in Figure 12a it may be observed that at a budget level of EUR $1.60 \times 10^{7}$ eight buildings are partially retrofitted (yellow tag) and two buildings fully retrofitted (orange tag), while in Figure 12b, at the 
next budget level (budget = EUR $1.64 \times 10^{7}$ ), nine buildings are partially retrofitted and one building is chosen for full retrofitting.

(a) - Budget $€ 1.60 \times 10^{7}$

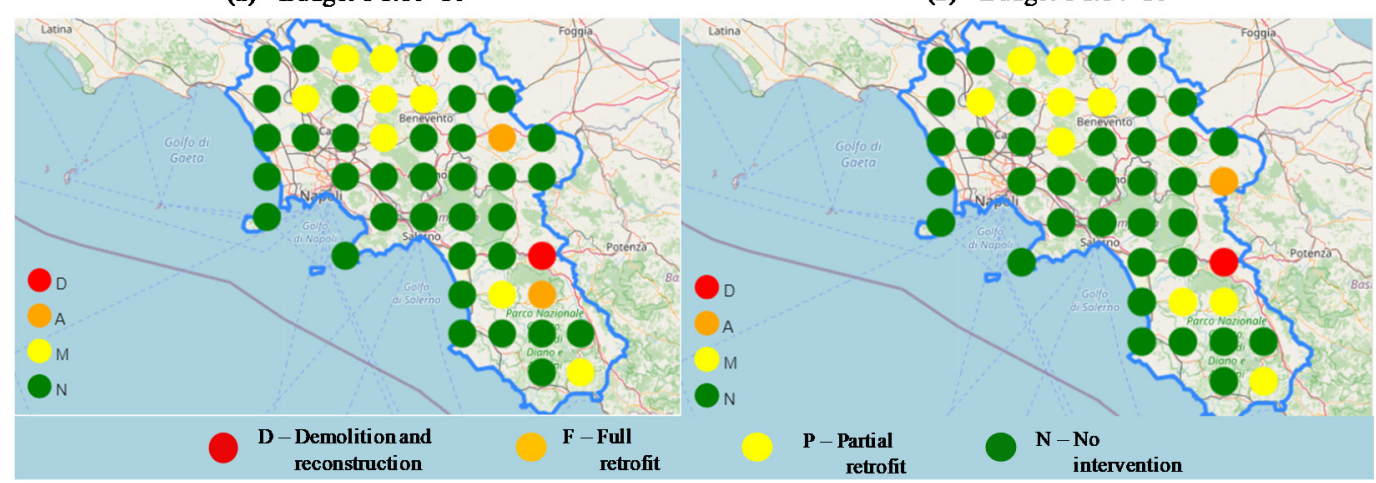

Figure 12. Map of the decision strategies for EUR $1.60 \times 10^{7}$ (a) and EUR $1.64 \times 10^{7}$ (b).

Considering that an "increase in the investment should make more risk reduction" justifies the observation of a reduction in the number of fully retrofitted buildings and an increase in the number of partial retrofittings. Actually, buildings have different vulnerability indexes and decision making is made through different decision cases according to Table 1. Given a certain budget level, it may be more convenient for risk mitigation to invest in the partial retrofit of a very vulnerable building (i.e., belonging to case 2 ) instead of fully retrofitting a building in a less severe condition (i.e., of case 3). Furthermore, the former intervention may be more expensive than the latter considering the lower value of the corresponding vulnerability index. Therefore, in such a scenario, the budget increase may result in a higher number of partially retrofitted buildings with respect to the fully retrofitted ones. It is interesting to observe that the fully retrofitting solution in Figure $12 \mathrm{~b}$ does not correspond to any of the two buildings tagged with the same retrofit intervention in Figure 12a. This is because buildings belonging to case 2 may equally be tagged as "no intervention", "full retrofit" or "partial retrofit". The final type of intervention indicated by the platform on the map results is the one that minimizes the territorial seismic risk within the budget limit.

In addition, the cumulative number of buildings decided for each decision category is provided in Figure 13, where each colored area denotes the portion of budget range allocated for those specified number of buildings. The general trend is that first the budget goes for partial retrofitting. For instance, for a budget value of EUR $0.5 \times 10^{7}$ there are three partial retrofitting solutions, one demolition and reconstruction, forty-two buildings with no interventions and no full retrofit solutions (Figure 14a). For a budget level of EUR $1.5 \times 10^{7}$, the number of partial retrofit solutions rises to eight, while the budget is used for a full retrofit intervention for no buildings (Figure 14b). In a different way, when the budget is further increased to the value of EUR 2. $5 \times 10^{7}$ (Figure 14c), the number of partial retrofit interventions decreases in favor of the number of full retrofit interventions, which in this case assume the same value (i.e., six buildings in partial retrofit and six buildings in full retrofit). This trend is confirmed when the maximum budget cost is achieved, which in this case corresponds to EUR $3.2 \times 10^{7}$ (Figure 14d). Indeed, at this level, no partial retrofit solutions are planned, while a total of 14 buildings are to be fully retrofitted. Increasing the budget level changes the type of intervention from partial to full retrofitting. From a certain budget level, more investment causes a decrease in partial and increase in full retrofitting until the maximum cost is achieved. At this point, the maximum risk has been lessened by the maximum possible full retrofitting for all buildings with $\chi<0.8$ (i.e., 15 buildings). 


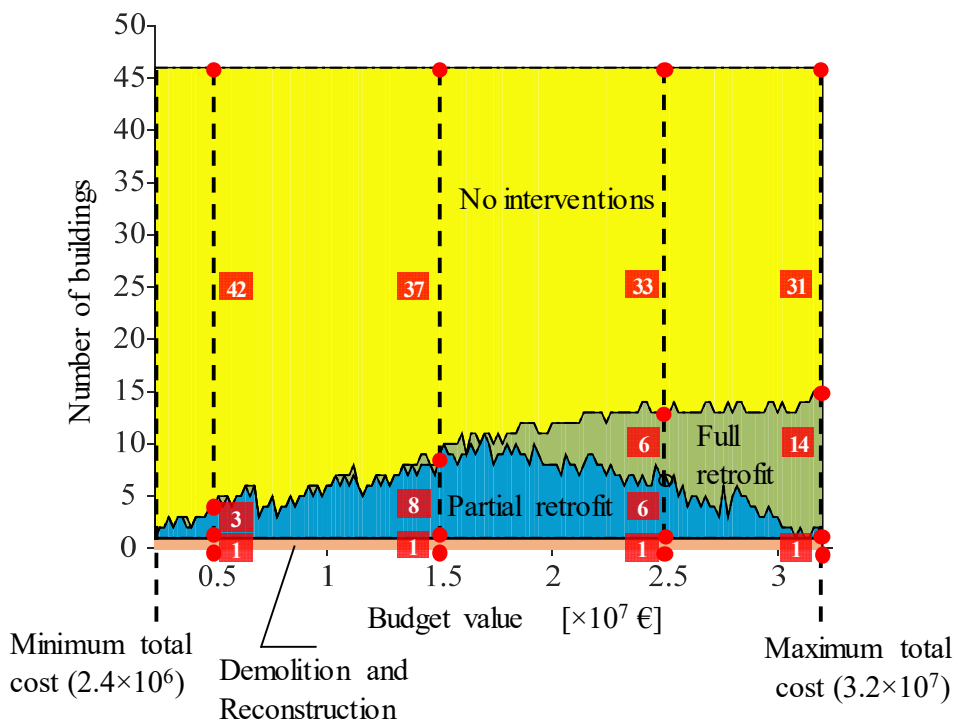

Figure 13. Portion of building numbers at each decision strategy for all the considered budget values.

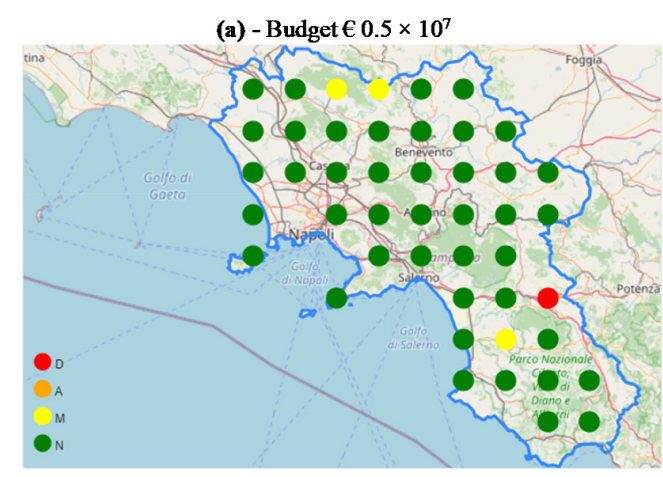

(c) - Budget $€ 2.5 \times 10^{7}$

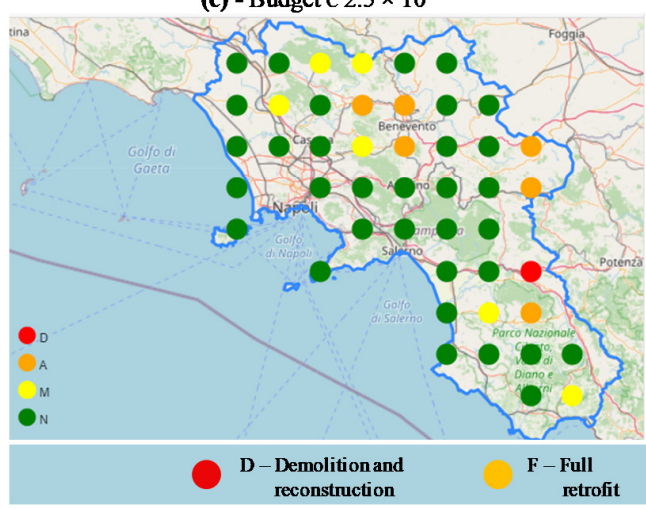

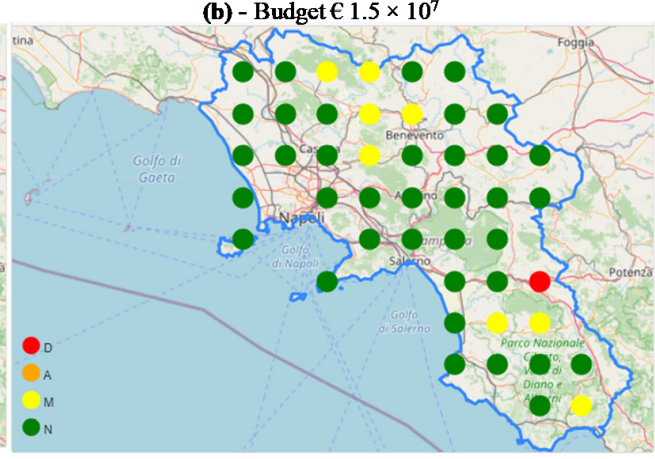

(d) - Budget $€ 3.2 \times 10^{7}$

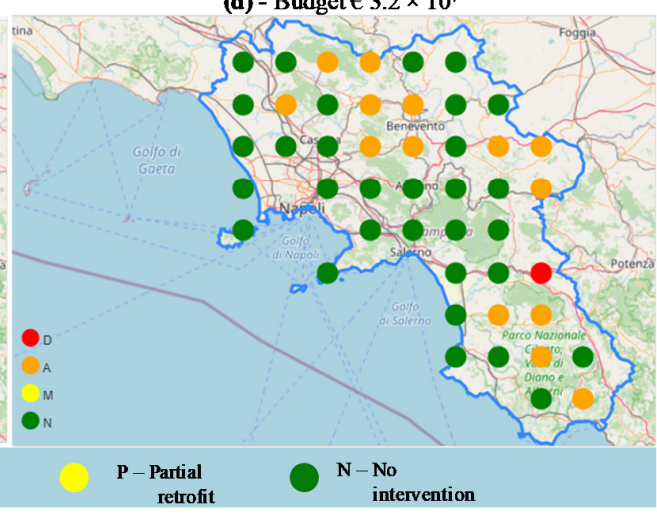

Figure 14. Decision strategies for budget value of: EUR $0.5 \times 10^{7}$ (a), EUR $1.5 \times 10^{7}(\mathbf{b})$, EUR $2.5 \times 10^{7}(\mathbf{c})$ and EUR $3.2 \times 10^{7}(\mathbf{d})$.

The sensitivity analysis allows for an overview of seismic risk mitigation as a function of the available budget. It enables decision-makers to highlight when it is worth increasing the investment designated to DRR or to save it for a more convenient use. As a matter of fact, analyzing the risk reduction curve of Figure 11, it is evident that the tangent to it has a descending slope as the budget rises. This means that at low values of the budget, small increases may produce a significant increase in the risk reduction. Conversely, at higher values of the budget, there may be only small enhancements in terms of risk reduction meaning it may not be worth raising the budget at all. 


\section{Conclusions}

In Italy, the allocation of budgets is unsystematic since no solid principle has been established. In this regard, decision makers face a challenge given that there are a large number of vulnerable buildings. This project was inspired by the idea from the aforementioned missing point in the seismic risk management of building portfolios. It attempts to develop a decision-making procedure to figure out how to distribute the budget not casually but wisely and with cogent reasoning. The study has been built on the platform of seismic risk analysis of buildings to understand how to manage budgets in order to lessen the future risk. The seismic risk is calculated in dimensions of monetary loss by combining the data of hazard, vulnerability and exposure. The algorithm for making decisions about how to reduce the seismic risk of an entire portfolio has been established by estimating the cost of retrofitting and calculating the benefit gained due to such an investment. The vulnerability index of buildings has been used to distinguish buildings that are vulnerable or not. Four intervention strategies have been assumed as possible interventions for each building: demolition/reconstruction, no intervention, partial retrofitting and full retrofitting. The best choice of intervention has been defined as that which meets both the needs and limits of the clients. From all of the combinations of interventions for each of the buildings the total cost and total seismic risk of post-intervention configuration can be calculated. The optimum selection of decision strategies is the one requiring a cost lower than the budget limit and yielding the minimum seismic risk in post-intervention. Finally, it is established how to intervene for each building and how much should be spent for each building to achieve the perceived minimum seismic risk.

A web platform system has been developed with the collaboration of ETT industrial partner within the framework of the GRISIS research project. The platform is able to provide a practical map of the seismic risk of a certain stock of RC buildings in the preintervention condition, particularly indicating the contribution of each building to the overall seismic risk of the portfolio. In a different section, geo-referenced data concerning a building's identity and geometry are stored. Then, an interactive section of the web system allows the user to insert the available budget to be allocated for the seismic risk mitigation. Knowing this, the system provides the optimal strategy for the budget's use and the corresponding post-intervention seismic risk map. In particular, the system is able to inform the user about (i) the retrofit intervention to adopt for each building of the portfolio, (ii) the post-intervention seismic risk in correspondence with each building and (iii) for the whole portfolio, (iv) the occurrence of each intervention typology in the portfolio and (v) the budget allocation for each type of intervention.

The use of the platform is shown through the applicative case study concerning the seismic risk mitigation of an RC school building portfolio distributed in the territory of the Campania region in south Italy. Supposing the availability of EUR $2.5 \times 10^{7}$ investment for the portfolio's seismic risk mitigation, the platform provides the best budget allocation corresponding with intervention on $28.3 \%$ of buildings. In particular, one building was to be demolished and rebuilt because it was characterized by very severe vulnerability, while $26 \%$ of buildings were equally distributed among partial and full retrofit solutions. An investment of $58.6 \%$ of the budget was spent on full retrofit interventions, while $32.1 \%$ was spent on partial retrofit buildings and $9.3 \%$ of the budget for the demolition and reconstruction. A sensitivity analysis concerning the variation of the budget value has shown that for lower values partial retrofitting is preferred with respect to full retrofit strategies. The trend is inverted when the budget rises. This observation is determined by searching for the decision that provides the biggest seismic risk reduction that can be achieved by spending the available budget in the partial retrofit of a higher number of buildings rather than in the full retrofit of fewer buildings.

The interactive web platform for seismic risk management and mitigation can be very useful to promptly know which is the optimal use of the investment, indicating the type of strategy to implement for each building of the portfolio. In addition, the ease of use enables the user to analyze the extent of risk reduction achievable for different budget 
levels. Therefore, the platform represents a powerful tool to accomplish two challenging tasks, namely optimal budget selection and optimal budget allocation to gain territorial seismic risk mitigation.

The algorithm for the definition of the optimal decision strategy is based on some simplifications that can be improved in future developments. The structural analysis is performed on 2D frames: the development of new simplified methods including more structural details will provide 3D analysis of buildings. Moreover, an improvement concerning the collection of building data will be provided thanks to the results achieved by the authors in relation to another research project (ARES) concerning the development of a platform gathering structural data and information on the state of maintenance in school buildings in the Campania region. This platform may be linked to communicate with the seismic risk mitigation platform proposed in this work in order to allow a prompt collection of the deterministic data needed to implement the framework. The final aim is to provide the public administrator with a practical, reliable and effective tool supporting decision-making for the management of territorial seismic risk mitigation.

Author Contributions: I.N.: data curation, validation, writing —original draft preparation, writingreview and editing. N.C.: conceptualization, methodology, validation, writing-review and editing; supervision. A.N.: software, validation. A.O.: funding acquisition, visualization, supervision. All authors have read and agreed to the published version of the manuscript.

Funding: This work is supported by the GRISIS project (Cup: B63D180002800079, Surf:18033BP000000001, DD MIUR prot. 36824 October 2018), implemented by STRESS scarl (www.stress-scarl.com, accessed on 14 June 2021) in the framework of FESR Campania 2014-2020.

Data Availability Statement: http:/ /151.1.25.86/GrisisWeb/Rischio, accessed on 14 June 2021.

Conflicts of Interest: The authors declare no conflict of interest. The funders had no role in the design of the study; in the collection, analyses, or interpretation of data; in the writing of the manuscript, or in the decision to publish the results.

\section{References}

1. Natural Disaster 2019, Emergency Events Database (EM-DAT). Centre for Research on the Epidemiology of Disasters (CRED). Available online: https:/ / www.emdat.be/publications (accessed on 14 June 2021).

2. Disaster Risk Reduction: A Global Advocacy Guide. International Federation of Red Cross and Red Crescent Societies (IFRC): 2012. Available online: https://www.ifrc.org/Global/Publications/disasters/reducing_risks/DRR-advocacy-guide.pdf (accessed on 14 June 2021).

3. Global Assessment Report (GAR) on Disaster Risk Reduction. United Nations Office for Disaster Risk Reduction (UNISDR): 2019. Available online: https://gar.undrr.org/sites/default/files/reports/2019-05/full_gar_report.pdf (accessed on 14 June 2021).

4. Sendai Framework for Disaster Risk Reduction 2015-2030. United Nations Office for Disaster Risk Reduction (UNISDR): 2015. Available online: https:/ /www.preventionweb.net/files/43291_sendaiframeworkfordrren.pdf (accessed on 14 June 2021).

5. Hyogo Framework: Building the Resilience of Nations and Communities to Disasters. United Nations Office for Disaster Risk Reduction (UNISDR): 2005. Available online: https://www.preventionweb.net/files/1037_hyogoframeworkforactionenglish.pdf (accessed on 14 June 2021).

6. Sendai Framework Monitoring System. United Nations Office for Disaster Risk Reduction. Available online: https://sendaimonitor. undrr.org/ (accessed on 14 June 2021).

7. Dolce, M.; Prota, A.; Borzi, B.; da Porto, F.; Lagomarsino, S.; Magenes, G.; Moroni, C.; Penna, A.; Polese, M.; Speranza, E.; et al. Seismic Risk Assessment of Residential Buildings in ITALY. Bull. Earthq. Eng. 2020, 19, 2999-3032. [CrossRef]

8. Borzi, B.; Onida, M.; Faravelli, M.; Polli, D.; Pagano, M.; Quaroni, D.; Cantoni, A.; Speranza, E.; Moroni, C. IRMA Platform for the Calculation of Damages and Risks of Italian Residential Buildings. Bull. Earthq. Eng. 2020, 19, 3033-3055. [CrossRef]

9. D'Alpaos, C.; Bragolusi, P. The market price premium for buildings seismic retrofitting. Sustainability 2020, 12, 8791. [CrossRef]

10. OECD (2018). Financial Management of Earthquake Risk. Available online: www.oecd.org/finance/Financial-Management-ofEarthquake-Risk.htm (accessed on 14 June 2021).

11. Nyimbili, P.; Erden, T.; Karaman, H. Integration of GIS, AHP and TOPSIS for earthquake hazard analysis. Nat. Hazards 2018, 92, 1523-1546. [CrossRef]

12. Cremen, G.; Galasso, C. A decision-making methodology for risk-informed earthquake early warning. Comput. Aided Civ. Infrastruct. Eng. 2021, 36, 747. [CrossRef]

13. Sadeghi, M.; Ghafory-Ashtiany, M.; Pakdel-Lahiji, N. Multi-objective optimization approach to define risk layer for seismic mitigation. Geomat. Nat. Hazards Risk 2017, 8, 257-270. [CrossRef] 
14. Vona, M.; Anelli, A.; Mastroberti, M.; Murgante, B. Prioritization Strategies to reduce the Seismic Risk of the Public and Strategic Buildings. Disaster Adv. 2017, 10, 21-34.

15. Asadzadeh Tarebari, S.; Amini Hosseini, K. Earthquake Risk-Management Model for Historic Commercial Urban Fabrics. Nat. Hazards Rev. 2020, 21, 05020002. [CrossRef]

16. Cardarilli, M.; Lombardi, M.; Guarascio, M. Preventive planning model for rescue priority management in seismic emergency. Int. J. Saf. Secur. Eng. 2018, 8, 307-319. [CrossRef]

17. Motamed, H.; Khazai, B.; Ghafory-Ashtiany, M.; Amini-Hosseini, K. An automated model for optimizing budget allocation in earthquake mitigation scenarios. Nat. Hazards 2014, 70, 51-68. [CrossRef]

18. Zolfaghari, M.R.; Peyghaleh, E. Implementation of equity in resource allocation for regional earthquake risk mitigation using two-stage stochastic programming. Risk Anal. 2015, 35, 434-458. [CrossRef] [PubMed]

19. Caterino, N.; Azmoodeh, B.M.; Manfredi, G. Seismic risk mitigation for a portfolio of reinforced concrete frame buildings through optimal allocation of a limited budget. Adv. Civ. Eng. 2018, 18. [CrossRef]

20. Iervolino, I.; Manfredi, G.; Polese, M.; Verderame, G.M.; Fabbrocino, G. Seismic risk of RC building classes. Eng. Struct. 2007, 29, 813-820. [CrossRef]

21. NTC08, 2008. D.M. 14 Gennaio, Norme Tecniche per le Costruzioni; Ministero delle Infrastrutture: Rome, Italy, 2008. (In Italian)

22. Borzi, B.; Pinho, R.; Crowley, H. Simplified pushover-based vulnerability analysis for large-scale assessment of RC buildings. Eng. Struct. 2008, 30, 804-820. [CrossRef]

23. Fajfar, P. Capacity spectrum method based on inelastic demand spectra. Earthq. Eng. Struct. Dyn. 1999, 28, 979-993. [CrossRef]

24. Eurocode 8-Design of Structures for Earthquake Resistance; EN 1998-1; CEN: Milan, Italy, 2004.

25. Asprone, D.; Jalayer, F.; Simonelli, S.; Acconcia, A.; Prota, A.; Manfredi, G. Seismic insurance model for the Italian residential building stock. Struct. Saf. 2013, 44, 70-79. [CrossRef]

26. Istruzioni per la Valutazione Affidabilistica Della Sicurezza Sismica di Edifici Esistenti 2013; Commissione di Studio per la predispozione e l'Analisi norme Tecniche Relative alle Costruzioni (CNR-DT 212 2013), Consiglio Nazionale delle Ricerche: Rome, Italy, 2013. (In Italian)

27. Masi, A.; Santarsiero, G.; Chiauzzi, L. Development of a seismic risk mitigation methodology for public buildings applied to the hospitals of Basilicata region (Southern Italy). Soil Dyn. Earthq. Eng. 2014, 65, 30-42. [CrossRef]

28. Available online: http:/ / ec.europa.eu/ipg/standards/accessibility/index_en.htm; http:/ /www.w3.org/WAI (accessed on 31 March 2021). 